\section{Prenatal diagnosis of transposition of the great arteries: an updated review}

\author{
Nathalie Jeanne Bravo-Valenzuela ${ }^{1,2}$, Alberto Borges Peixoto ${ }^{3,4}$, Edward Araujo Júnior ${ }^{1}$ \\ 'Department of Obstetrics, Paulista School of Medicine, Federal University of São Paulo \\ (EPM-UNIFESP), São Paulo; ${ }^{2}$ Department of Pediatrics, Pediatric Cardiology, Federal University \\ of Rio de Janeiro (UFRJ), Rio de Janeiro; ${ }^{3}$ Mário Palmério University Hospital, University of \\ Uberaba (UNIUBE), Uberaba; ${ }^{4}$ Department of Obstetrics and Gynecology, Federal University \\ of Triângulo Mineiro (UFTM), Uberaba, Brazil
}

Simple transposition of the great arteries (TGA) is a cyanotic heart disease that accounts for $5 \%$ to $7 \%$ of all congenital heart diseases. It is commonly underdiagnosed in utero, with prenatal detection rates of less than $50 \%$. Simple TGA is characterized by ventriculoarterial discordance, atrioventricular concordance, and a parallel relationship of TGA. The prenatal diagnosis of TGA influences postnatal outcomes and therefore requires planned delivery and perinatal management. For these reasons, it is important to identify the key ultrasound markers of TGA to improve the prenatal diagnosis and consequently provide perinatal assistance. The presence of two vessels instead of three in the three-vessel tracheal view, a parallel course of TGA, and identification of the origin of each of TGA are the key markers for diagnosing TGA. In addition to the classical ultrasound signs, other two-dimensional ultrasound markers such as an abnormal right convexity of the aorta, an I-shaped aorta, and the "boomerang sign" may also be used to diagnose TGA in the prenatal period. When accessible, an automatic approach using fourdimensional technologies such as spatio-temporal image correlation and sonographically-based volume computer-aided analysis may improve the prenatal diagnosis of TGA. This study aimed to review the ultrasound markers that can be used in the antenatal diagnosis of TGA, with a focus on the tools used by ultrasonographers, the obstetric and fetal medicine team, and perinatal cardiologists to improve the diagnosis of this condition.

Keywords: Prenatal diagnosis; Ultrasound cardiac screening; Fetal echocardiography;

Transposition of the great arteries

\section{Introduction}

The diagnosis of several congenital heart diseases (CHDs) has improved by evaluating the outflow tracts in the four-chamber view during cardiac screening and by using advanced ultrasound technologies such as three-dimensional (3D) and four-dimensional (4D) ultrasonography/ echocardiography [1-3]. However, simple transposition of the great arteries (TGA) is one of the CHDs that is most commonly underdiagnosed in utero. In most prenatal series, the reported detection rate of TGA is less than $50 \%[4-8]$.

e-ultrasonography.org

Ultrasonography 39(4), October 2020

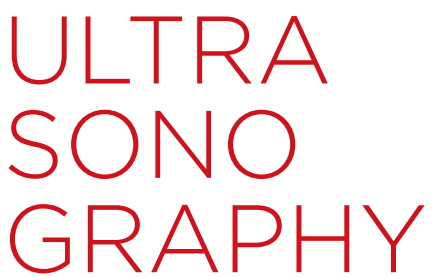

\section{REVIEW ARTICLE}

https://doi.org/10.14366/usg.20055 pISSN: 2288-5919 • elSSN: 2288-5943 Ultrasonography 2020;39:331-339

Received: April 18, 2020

Revised: June 6, 2020

Accepted: June 8, 2020

Correspondence to:

Edward Araujo Júnior, PhD, Department of Obstetrics, Paulista School of Medicine, Federal University of São Paulo (EPM-UNIFESP), Rua Belchior de Azevedo, 156 apto. 111 Torre Vitoria, São Paulo, CEP 05089-030, Brazil

Tel. +55-11-37965944

Fax. +55-11-37965944

E-mail: araujojred@terra.com.br

This is an Open Access article distributed under the terms of the Creative Commons Attribution NonCommercial License (http://creativecommons.org/ licenses/by-nc/4.0/) which permits unrestricted noncommercial use, distribution, and reproduction in any medium, provided the original work is properly cited.

Copyright @ 2020 Korean Society of Ultrasound in Medicine (KSUM)

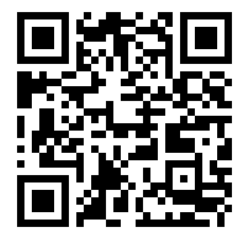

How to cite this article:

Bravo-Valenzuela NJ, Peixoto AB, Araujo Júnior $E$. Prenatal diagnosis of transposition of the great arteries: an updated review. Ultrasonography. 2020 0ct;39(4):331-339. 
TGA, which comprises $5 \%$ to $7 \%$ of all CHDs, is characterized by ventriculoarterial (VA) discordance, atrioventricular (AV) concordance, and a parallel relationship of TGA [9-12]. Due to the presence of abnormalities in the ventricular outflow tract, a variety of key ultrasound markers involving the left ventricle (LV) and right ventricle (RV) outflow tracts have been described. The presence of two vessels instead of three in the three-vessel tracheal view, a parallel course of TGA, and identification of the origin of each of TGA are the key markers for diagnosing this condition [1315]. However, the reasons for the low rate of TGA detection in the prenatal period remain unclear. Classically, the fetal diagnosis of TGA is based on identification of the bifurcation of the great vessel (pulmonary artery), which arises from the posterior ventricle (LV), and is aided by the parallel course of TGA. However, the pulmonary artery branches at the LV outflow tract view are difficult to visualize. This fact may explain why the prenatal diagnosis of TGA remains a challenge, especially in patients with simple TGA whose fourchamber view appears normal.

TGA is one of the most common causes of cyanosis and is a lifethreatening neonatal cardiac malformation. The prenatal diagnosis of TGA may have an impact on postnatal outcomes and therefore requires planned delivery and perinatal management $[3,7,8,16,17]$. Accordingly, this study aimed to review the ultrasound markers that can be used in the antenatal diagnosis of TGA, with a focus on the tools used by ultrasonographers, the obstetric and fetal medicine team, and perinatal cardiologists to improve the diagnosis.

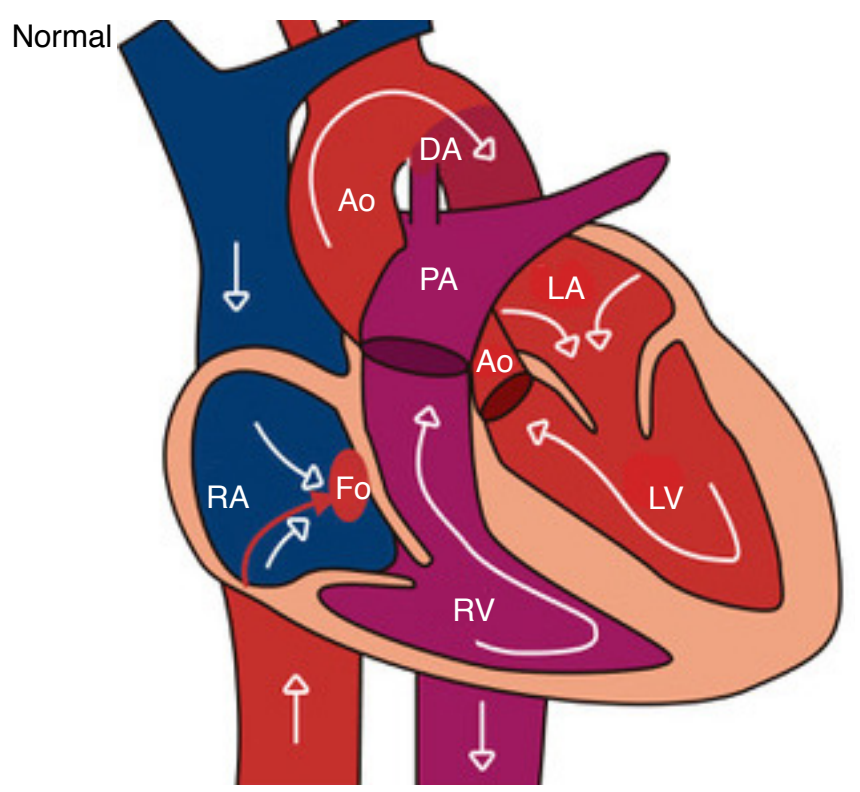

\section{TGA: Terminology and Morphology}

TGA is a CHD in which the aortic artery emerges from the anterior ventricle (morphological RV) while the pulmonary artery originates from the posterior ventricle (morphological LV). Previous definitions of TGA highlighted the abnormal relationship between TGA, which led to the inclusion of other cardiac malformations such as doubleoutlet RV, univentricular AV connections ("single ventricles"), or tricuspid atresia. In this setting, the term "complete TGA" was used to avoid ambiguity in the description of TGA. Complete transposition is characterized by AV concordance and VA discordance and can exist with a normal (solitus) or mirror-imaged (inversus) arrangement of the atria, but this category does not include hearts with atrial isomerism (Fig. 1). It is important to differentiate between TGA and congenitally corrected transposition of TGA, which is characterized by ventricular inversion aided by a transposed relationship of TGA (discordant VA and AV connections) (Fig. 2).

The primary morphological characteristics of TGA are follows: (1) the atria connect to their respective ventricles (AV concordance) with disagreement of the arteries in relation to the ventricles (VA discordance), (2) the interventricular septum does not present the normal curvature of a normal heart, and (3) TGA are in a parallel arrangement, and the aortic valve is positioned anteriorly and to the right of the pulmonary valve (dextro-TGA [d-TGA]) $[18,19]$.

The types of TGA are as follows: d-TGA, in which the aortic valve is positioned at the front and the right side of the pulmonary valve;

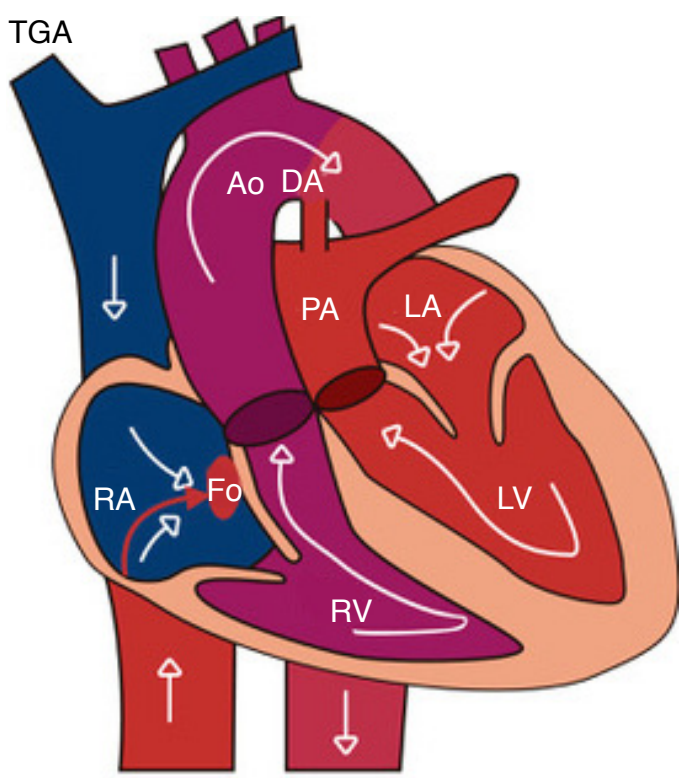

Fig. 1. Schematic of the normal circulation and the abnormal circulation in transposition of the great arteries. The schematic images show the normal physiological circulation and the parallel circulation in transposition of the great arteries (fetal circulation). Ao, aorta; $\mathrm{DA}$, ductus arteriosus; Fo, foramen ovale; LA, left atrium; LV, left ventricle; PA, pulmonary artery; RA, right atrium; RV, right ventricle; TGA, transposition of the great arteries. 
levo-TGA, in which the aortic valve is located at the left of the pulmonary valve; simple TGA, where there are no associated cardiac anomalies; and complex TGA, in which the transposed arteries coexist with other cardiac malformations. Simple TGA is more common than the complex form [20]. The more common associated cardiac anomalies are ventricular septal defects (with a certain degree of malalignment of the outlet septum) and LV or RV outflow tract obstructions. If the outlet septum is deviated posteriorly and leftward, sub-pulmonary stenosis is suspected. On the contrary, when the outlet septum is deviated anteriorly and rightward, subaortic stenosis may occur with a fibrous continuity between the pulmonary and mitral valves. LV outflow tract (LVOT) obstruction is more common in TGA patients with ventricular septal defect. Other congenital cardiac anomalies are coronary anomalies, right aortic arch, and anomalous venous connections (systemic or pulmonary veins). These anomalies are more frequent in TGA patients with ventricular septal defects.

Chromosomal and extracardiac anomalies are rarely present in patients with TGA; therefore, controversy remains regarding whether fetal karyotype collection is indicated. This CHD is more frequent in fetuses of pregnant women with pre-gestational diabetes mellitus, with a history of exposure to pesticides, or with a history of retinoic acid use (first trimester) $[5,21]$.

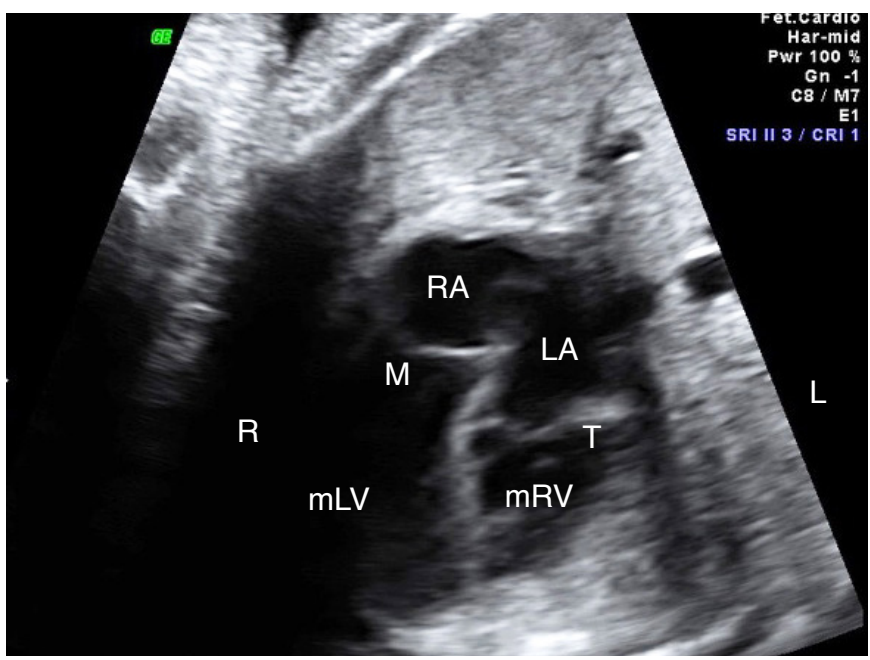

Fig. 2. Abnormal four-chamber view in congenitally corrected transposition of the great arteries. Note that the anatomical right ventricle is on the left and the anatomical left ventricle is on the contralateral side. The ventricular inversion aided by a transposed relationship of the great arteries enables this diagnosis by fetal cardiac ultrasonography. $L$, left side; $L A$, left atrium; $M$, mitral valve; $\mathrm{mLV}$, morphological left ventricle; $\mathrm{mRV}$, morphological right ventricle; $R$, right side; $R A$, right atrium; $T$, tricuspid valve.

\section{Methods}

For this review, a search strategy was constructed to identify studies on the prenatal diagnosis of TGA published in English in PubMed from 2007 to 2020. The following Medical Subject Headings terms were used: "prenatal diagnosis," "ultrasound cardiac screening," "fetal echocardiography," "transposition of the great arteries," and "transposition of vessels." Studies were analyzed if they were published between 2007 and March 2020 and evaluated the key ultrasound markers used in making the antenatal diagnosis of TGA. Case reports, review studies, duplicate studies, studies on predictors of neonatal outcomes of TGA, and those that aimed at examining the impact of the prenatal diagnosis of TGA on postnatal outcomes were excluded. A total of 82 related manuscripts were found after screening titles and abstracts. After applying the inclusion and exclusion criteria, the full text of six manuscripts was examined. Two studies were added after analyzing the selected studies and their references, for a total of eight studies that were selected (Fig. 3).

\section{Prenatal Diagnosis of TGA by Ultrasonography and Echocardiography}

The guidelines for fetal cardiac screening examination and training programs can maximize the detection rates of CHD, especially in low-risk fetuses. Since 2013, the International Society of Ultrasound

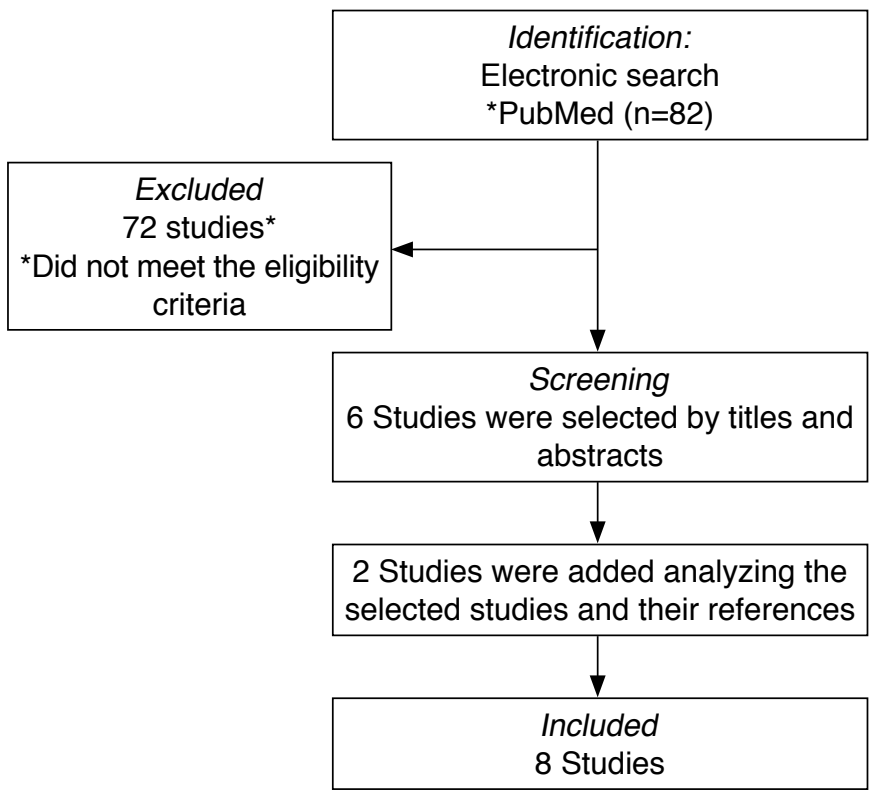

Fig. 3. Flowchart of the inclusion of articles for review. The flowchart shows the records which were identified after an electronic search of the manuscripts that were published during 2007 to 2020 on the prenatal ultrasound marks used in making the diagnosis of transposition of the great arteries. 
in Obstetrics and Gynecology and the American Institute of Ultrasound in Medicine added evaluation of the outflow tracts to the four-chamber view for cardiac ultrasound screening. This approach improved the sensitivity of ultrasound screening for CHD from approximately $30 \%$ to $69 \%-83 \%$ [2]. In this setting, the threevessel view and three-vessel tracheal view were also included in the cardiac ultrasound screening protocol, which involves evaluating the aorta, pulmonary artery, and superior vena cava [2]. The assessment of the size, alignment, and arrangement of those vessels was performed at the aforementioned upper mediastinum views [13,2224]. Despite improvements in cardiac screening and its impact on a variety of CHDs, the antenatal diagnosis of TGA has not improved. Consequently, this study aimed to review studies published from 2007 to March 2020 that described the ultrasound markers of TGA and important tools for making the fetal diagnosis of TGA.

In 2007, McGahan et al. [25] described nine neonates with TGA, of whom four were diagnosed in utero. The mortality rate in neonates with no prenatal diagnosis of TGA was $25 \%$, while that in neonates with a prenatal diagnosis was $0 \%$, with an overall mortality of $11 \%$. In this retrospective review, the techniques used in performing obstetric ultrasonography and fetal echocardiography of patients with TGA $(n=9)$ were revised. In TGA patients with associated cardiac anomalies, cardiac abnormalities were shown on the four-chamber view (abnormal cardiac axis, ventricular septal defect, and size discrepancy of cardiac chambers), and this condition could be more easily detected during the prenatal period than simple TGA. After reviewing the cine clips of patients whose diagnosis of TGA was missed, the researchers observed that the outflow tract views can be used to detect this CHD prenatally. The authors suggested that the best method to diagnose TGA is to assess the outflow tract based on the following steps: (1) the relationship between the aorta and pulmonary artery should be determined (Fig. 4), (2) the anatomic characteristics of the arteries arising from each ventricle should be defined (Fig. 5), and (3) the LVOT should be carefully assessed to determine whether an arch or a bifurcation of TGA arises from the LV. Fetuses with TGA have abnormal outflow tracts showing a parallel relationship with TGA

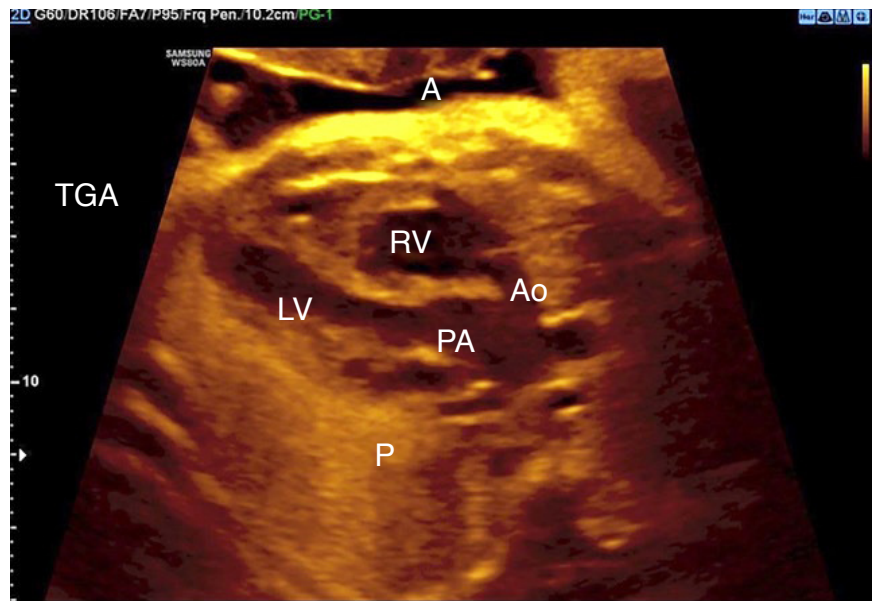

Fig. 4. Parallel relationship of the great arteries in transposition of the great arteries. Outflow tract views show the parallelism of the great arteries in transposition of the great arteries (aorta $[A 0]$, anterior $[A]$ and pulmonary artery $[P A]$, posterior $[P])$. LV, left ventricle; $R V$, right ventricle; TGA, transposition of the great arteries.

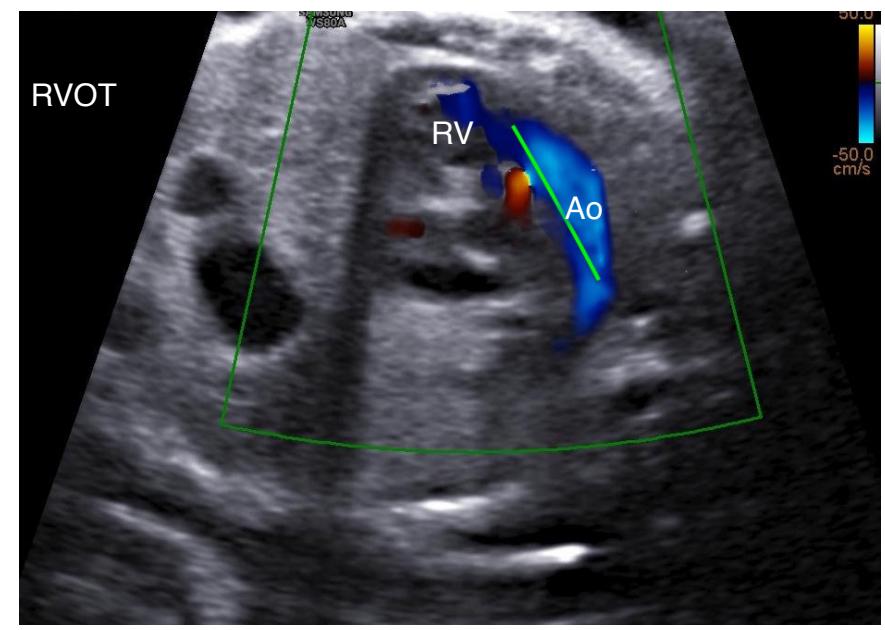

A

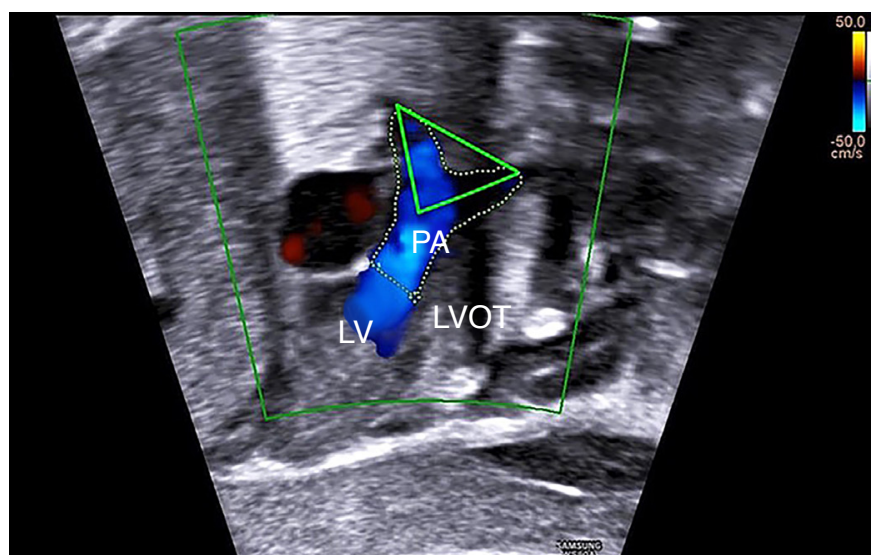

B

Fig. 5. Characteristics of the ventricular outflow tracts in transposition of the great arteries.

A fetal echocardiogram performed at 29 weeks of gestation shows the characteristics of each vessel in the right and left outflow tracts. Note that the aorta $(\mathrm{Ao})$ arises from the right ventricle (RV) and appears as a long vessel $(A)$, while the pulmonary artery (PA) originates from the left ventricle (LV), which presents as a bifurcation and appears triangular in shape (B). LVOT, LV outflow tract; RVOT, RV outflow tract. 
and with the vessel bifurcation (pulmonary artery) arising from the LVOT. The authors highlighted the importance of demonstrating that the pulmonary artery arises from the LV, with the image of its bifurcation resembling the head of a baby bird with an open beak. This sign was described as the "baby bird's beak image" (Fig. 6).

In 2008, Rizzo et al. [26] showed that the use of sonographicallybased volume computer-aided analysis (sonography-based automated volume count [sono-AVC]) software enabled automatic

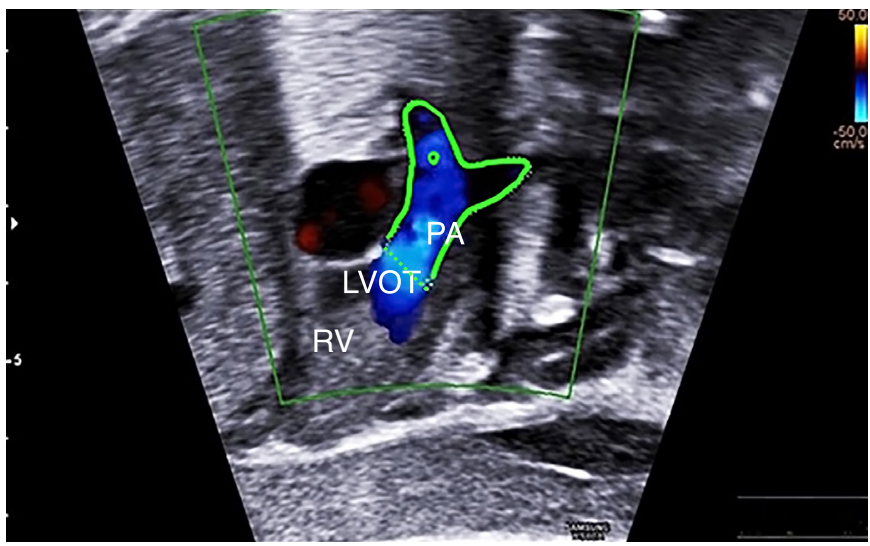

Fig. 6. The "baby bird's beak" sign. The left ventricle outflow tract (LVOT) view shows that the pulmonary artery (PA) arises from the left ventricle in a case of transposition of the great arteries. Note that the bifurcation of PA forms an image of a bird's beak. RV, right ventricle. retrieval of the abnormal ventricular outflow tracts in all fetuses with TGA included in their study. The 4D spatio-temporal image correlation (STIC) cardiac volumes of 12 fetuses with TGA at 18 to 23 weeks of gestation were retrospectively evaluated. Ten of the fetuses had TGA and the other two had congenitally corrected TGA. This study demonstrated that the automatic reconstruction of the ventricular outflow tracts using this technique (sono-AVC) may facilitate the identification of abnormal AV connections. Furthermore, the results of this study were in agreement with the data presented by Vinals et al. [15], who used a manual multiplanar approach on 4D STIC volumes in fetuses with TGA (Fig. 7). Indeed, Rizzo et al. [26] concluded that this automatic approach (sonoAVC) may improve the prenatal diagnosis of TGA by showing the automatic reconstruction of the outflow tracts from a $4 \mathrm{D}$ cardiac volume acquired from a standard four-chamber view. Studies have described the advantages of $3 \mathrm{D}$ and $4 \mathrm{D}$ ultrasonography in the diagnosis of CHD [15,27-29]. However, those technologies are not always available on ultrasound machines during routine obstetric cardiac screening and/or fetal echocardiography.

Moreover, Shih et al. [30] presented a retrospective analysis of cardiac volumes using the STIC technique in 56 fetuses with CHD and 30 controls. The authors observed that in those with TGA (10 of 56 fetuses), the great vessels were disposed side by side, resembling a Japanese fictional character, created by Sanrio, called "Keroppi" (Fig. 8). This sign was described as the "big-eyed frog" and was

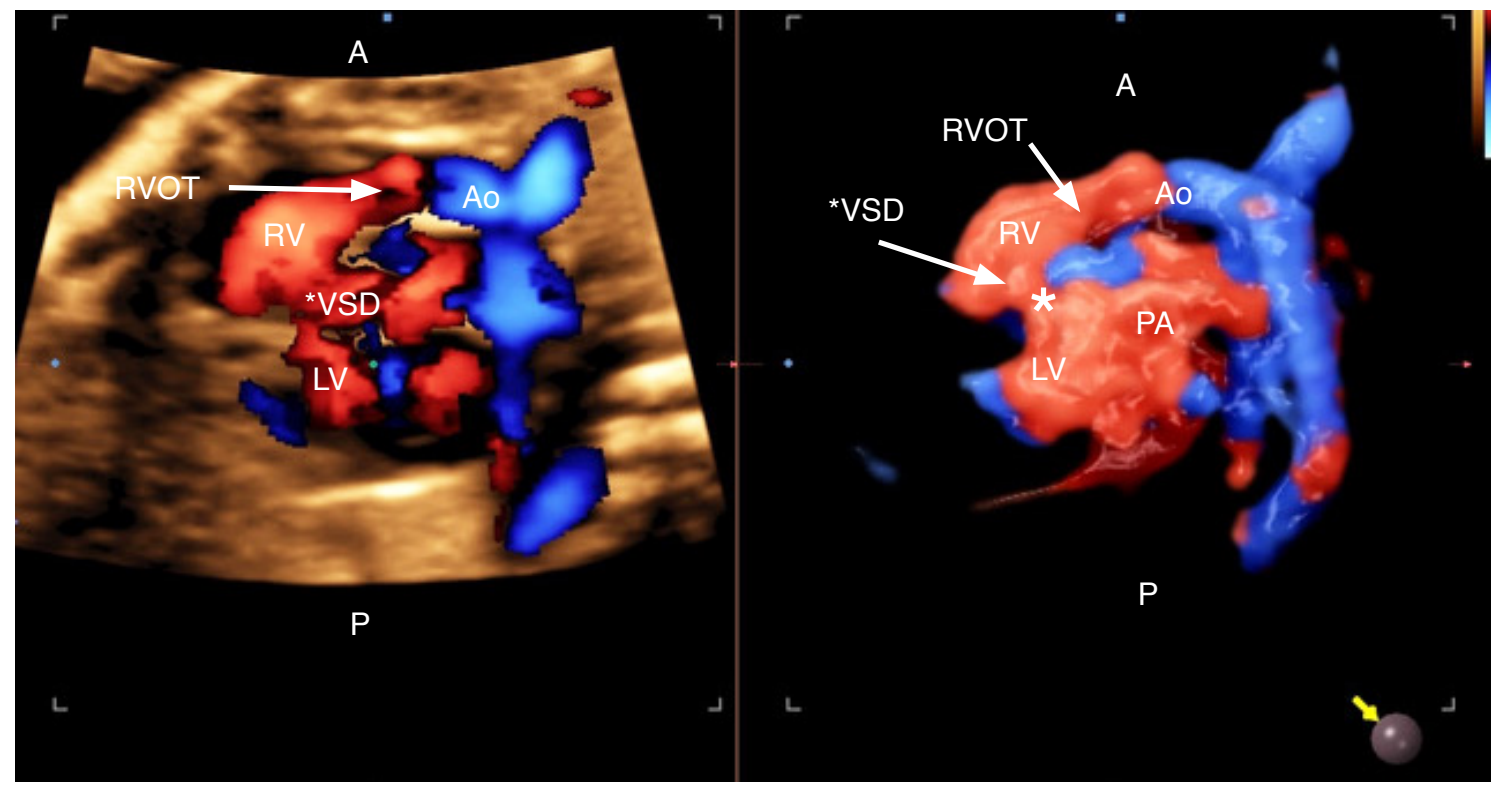

Fig. 7. Assessment of the abnormal relationship of the great arteries using spatio-temporal image correlation software with color Doppler ultrasonography in transposition of the great arteries. The aorta (Ao) is located anteriorly and to the right of the pulmonary artery (PA). This advanced technology enables the reconstruction of the outflow tracts off-line in patients with transposition of the great arteries and ventricular septal defect. A, anterior; LV, left ventricle; P, posterior; RV, right ventricle; RVOT, RV outflow tract; VSD, ventricular septal defect. 
found to be useful in improving the diagnosis of TGA.

Tongsong et al. [31] evaluated the effectiveness of the threevessel tracheal view in 106 fetuses diagnosed with CHD, and reported a detection rate of $70.8 \%$. In this study, only two vessels (aorta and superior vena cava) were detected in all fetuses with TGA instead of three in the three-vessel tracheal view ("misnomer three vessels") (Fig. 9). However, this is not a pathognomonic sign of TGA, since in truncus arteriosus and double-outlet RV, the threevessel tracheal view is a misnomer due to the abnormal relationship between TGA in which the aorta is located anteriorly. Furthermore,

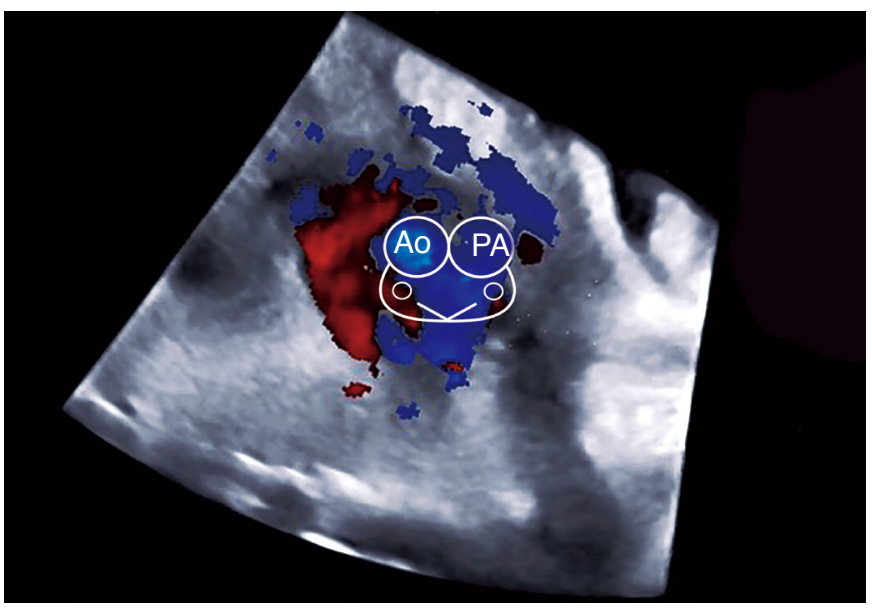

Fig. 8. The "big-eyed frog" sign detected using spatio-temporal image correlation in transposition of the great arteries. Note that the main pulmonary artery (PA) is situated side by side with the aorta (Ao), resembling the Sanrio frog character ("Keroppi"). other studies demonstrated that the "misnomer three vessels" is not present in all cases of TGA, especially in the three-vessel tracheal view $[15,30]$. In this setting, this finding provides a strong suspicion of TGA, but it is not a pathognomonic sign since it can also be observed in fetuses with common arterial trunk and some forms of double-outlet RV. Consequently, additional ultrasound findings have been used to improve the diagnosis of TGA in fetuses.

In 2013, Menahem et al. [32] reviewed 21 fetuses whose prenatal diagnosis of TGA was confirmed postnatally. In all cases of TGA, the authors observed an abnormal right convexity of the vessel

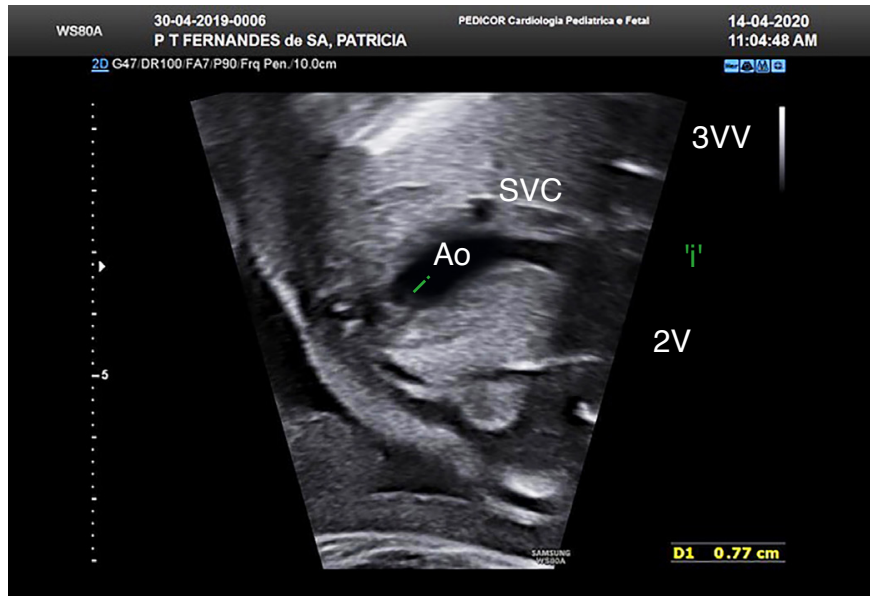

Fig. 9. Three-vessel (3V) view in a fetus with transposition of the great arteries. The 'misnomer $3 V^{\prime}$ ': only two vessels (aorta $[\mathrm{Ao}]$ and superior vena cava $[\mathrm{SVC}]$ ) are identified in this view due to the anterior position of the Ao in relation to the pulmonary artery. The arterial vessel appears as a long vessel (Ao) with a marked "I-shape". 2V, two-vessel view; 3VV, three-vessel view.

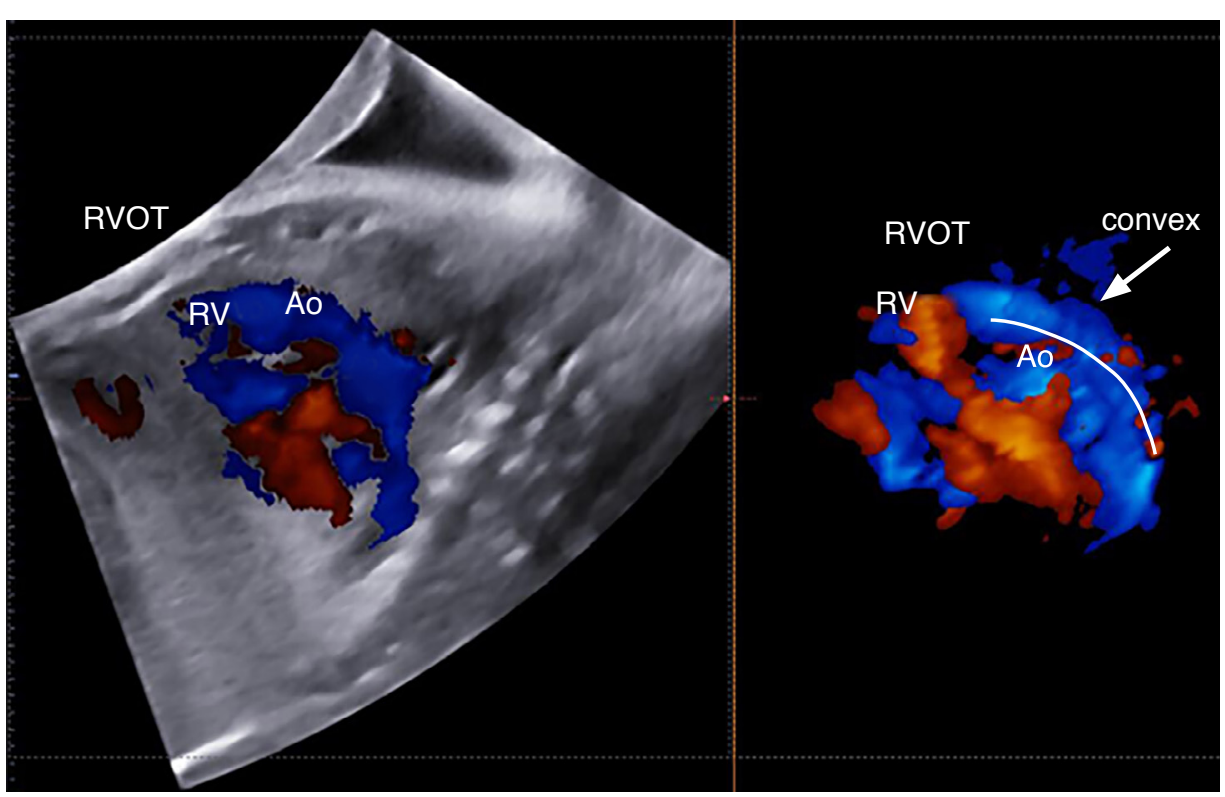

Fig. 10. Assessment of the right ventricle (RV) outflow tract (RVOT) view in a case of transposition of the great arteries. Fetal echocardiogram of a fetus with simple transposition of the great arteries at 28 weeks of gestation shows the rightward (convex) curvature of the RVOT. Ao, aorta. 
Table 1. Summary of the reviewed articles

\begin{tabular}{|c|c|c|c|}
\hline Study & $\begin{array}{l}\text { No. of cases with } \\
\text { d-TGA }\end{array}$ & $\begin{array}{l}\text { Gestational age } \\
\text { (wk) }\end{array}$ & Conclusion \\
\hline McGahan et al. (2007) [25] & $\begin{array}{l}9 \\
\text { (4 diagnosed } \\
\text { in utero) }\end{array}$ & $18-24$ & $\begin{array}{l}\text { This study observed that the detailed analysis of the outflow tract views were the } \\
\text { keys for performing the prenatal detection of TGA: a parallel relationship of great } \\
\text { arteries and bifurcation of the vessel (pulmonary artery) arising from the LVOT. }\end{array}$ \\
\hline Rizzo et al. (2008) [26] & 10 & $18-23$ & $\begin{array}{l}\text { The authors demonstrated that automatic reconstruction of the ventricular outflow } \\
\text { tracts by STIC with sono-AVC may improve the prenatal diagnosis of TGA. All fetuses } \\
\text { with TGA included in this study were diagnosed by using this technology. }\end{array}$ \\
\hline Shih et al. (2008) [30] & 10 & $21-37$ & $\begin{array}{l}\text { It was demonstrated that the great arteries in TGA are positioned side-by-side } \\
\text { by applying the STIC software, resembling a Japanese fictional character, created } \\
\text { by Sanrio, called "Keroppi." The authors named this the "big-eyed frog" sign and } \\
\text { concluded that it may be useful for improving the prenatal diagnosis of TGA. }\end{array}$ \\
\hline Tongsong et al. (2010) [31] & 5 & $\begin{array}{c}16-39 \\
(\text { mean, 26) }\end{array}$ & $\begin{array}{l}\text { In this study, the authors observed there were only two vessels (aorta and superior } \\
\text { vena cava) in all cases of TGA instead of three in the 3VV ("misnomer } 3 \text { vessels"). }\end{array}$ \\
\hline Menahem et al. (2013) [32] & 21 & $\begin{array}{l}\text { First and second } \\
\text { trimesters }\end{array}$ & $\begin{array}{l}\text { In all cases of TGA, the authors observed an abnormal right convexity of the vessel } \\
\text { (aorta) arising from the RV instead the normal convexity to left observed in normal } \\
\text { hearts, in which the pulmonary artery is the vessel arising from RV. }\end{array}$ \\
\hline Ishii et al. (2013) [33] & 31 & $16-41$ & $\begin{array}{l}\text { The authors described the "I-sign." The long vessel (aorta) arising from the RV (the } \\
\text { "I-shaped" vessel) was observed in } 96.8 \% \text { of cases of TGA. }\end{array}$ \\
\hline Palatnik et al. (2015) [34] & 24 & $18-26$ & $\begin{array}{l}\text { The authors observed the "I-sign" in all fetuses with d-TGA in the 3V and 3VT and } \\
\text { concluded that this sign is an important tool for the prenatal diagnosis of TGA. }\end{array}$ \\
\hline Ravi et al. (2018) [35] & $\begin{array}{l}127 \\
\text { (prenatal diagnosis: } \\
\mathrm{n}=47 \text { ) }\end{array}$ & $\begin{array}{c}21 \pm 3 \\
(\text { mean })\end{array}$ & $\begin{array}{l}\text { The authors attributed the temporal increase on the antenatal diagnosis of TGA to } \\
\text { improvements in outflow tract screening that were aided by the four-chamber view } \\
\text { on routine obstetric ultrasound in accordance with the corresponding. }\end{array}$ \\
\hline $\begin{array}{l}\text { Bravo-Valenzuela et al. } \\
\text { (2019) [36] }\end{array}$ & 8 & First trimester & $\begin{array}{l}\text { In this study, the rightward convex curvature of the RV outflow that was described } \\
\text { previously by Menahem et al. [32] was described as the "boomerang sign." The } \\
\text { authors concluded that the boomerang sign is an easier and earlier novel marker of } \\
\text { TGA, highlighting the importance of having a spatial understanding of the reverse } \\
\text { curvature of the RVOT that occurs in TGA. }\end{array}$ \\
\hline
\end{tabular}

d-TGA, dextro-transposition of the great arteries; TGA, transposition of the great arteries; LVOT, left ventricle outflow; STIC, spatio-temporal image correlation; sono-AVC, sonography-based automated volume count; 3VV, three-vessel view; RV, right ventricle; 3V, three vessels; $3 \mathrm{VT}$, three vessels and trachea view; RVOT, right ventricle outflow.

(aorta) arising from the RV instead of the normal convexity to the left observed in normal hearts, in which the pulmonary artery arises from the RV. The rightward convexity of the great artery arising from the RV (aorta) was a reliable clue for diagnosing TGA (Fig. 10). In fetuses with TGA, two vessels were demonstrated in the three-vessel tracheal view.

In 2013, Ishii et al. [33] described a novel echocardiographic marker for the prenatal diagnosis of TGA, an I-shaped aorta. In this retrospective study, the data of 671 patients with CHD were reviewed, of whom 31 had TGA. The "I-sign" was observed in 96.8\% of fetuses with TGA and in $4.8 \%$ of fetuses with other CHDs. The authors suggested that the long vessel (aorta) arising from the RV ("I-shaped") should increase clinicians' suspicion of TGA during routine ultrasound examinations (Fig. 9). Two years later, Palatnik et al. [34] reviewed 24 fetuses with a prenatal diagnosis of TGA (from 18 to 26 weeks of gestation) focusing on the I-sign and concluded that this sign is an important tool in diagnosing TGA. Moreover, the I-sign was observed in all fetuses with d-TGA in whom the threevessel and three-vessel tracheal views were successfully obtained.

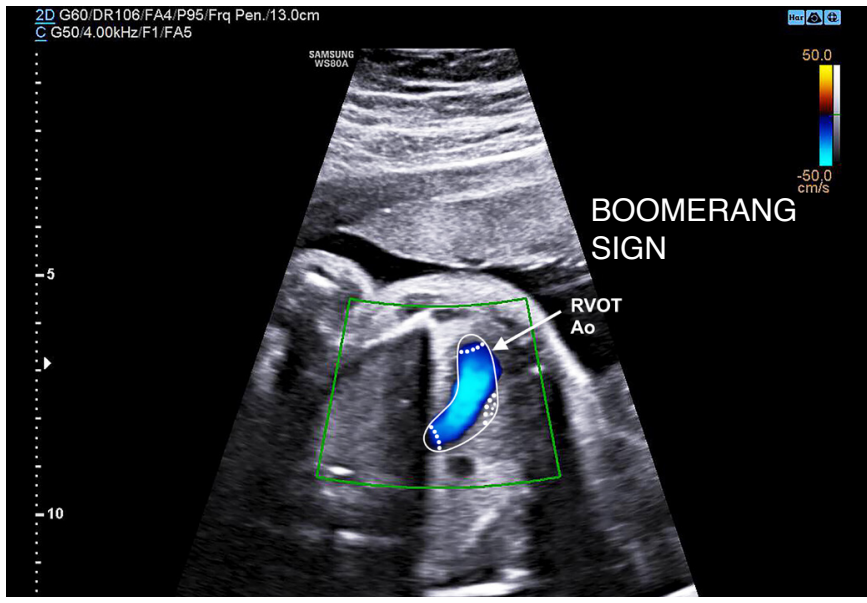

Fig. 11. The "boomerang sign". A first-trimester fetal echocardiogram shows reverse curvature of the right ventricle outflow tract (RVOT) with a shape of a boomerang in a case of transposition of the great arteries. Ao, aorta. 
In 2018, Ravi et al. [35] reviewed 127 fetuses with TGA between 2003 and 2015 in Alberta, Canada. Of them, 37\% ( $n=47)$ were diagnosed with TGA prenatally; however, the detection rate increased from $14 \%$ in $2003-2010$ to $77 \%$ in 2015 . In this study, the increase in the rate of antenatal diagnosis of TGA was attributed to improvements in outflow tract screening aided by a four-chamber view on routine obstetric ultrasound performed in accordance with the corresponding guidelines.

In 2019, Bravo-Valenzuela et al. [36] reviewed eight fetuses whose prenatal diagnosis of TGA at the first trimester was confirmed postnatally. In all fetuses with TGA, two vessels instead of three were detected on the three-vessel view, and the reverse curvature of the vessel (aorta) was found to be arising from the RV. By contrast, the RV outflow in fetuses with normal heart presents a leftward curvature (pulmonary artery). In this study, the rightward convex curvature of the RV outflow that was described previously by Menahem et al. [32] was referred to as the "boomerang sign" (Fig. 11). This sign served as a clue in diagnosing TGA in all cases. This study concluded that the boomerang sign is an easier and earlier novel marker of TGA, highlighting the special importance of understanding the reverse curvature of the RV outflow tract that occurs in TGA, with a focus on improving this diagnosis. The studies analyzed in the present study are described in Table 1.

\section{Conclusion}

TGA is a critical CHD; however, it remains underdiagnosed prenatally. Therefore, the antenatal diagnosis of TGA, especially in cases of simple d-TGA, is crucial in reducing the morbidity and mortality related to this cardiac anomaly. Accordingly, it is important to determine reliable clues for diagnosing TGA by obstetric cardiac screening and fetal echocardiography. In this setting, the "misnomer three vessels" in which only two vessels are identified provides a strong suspicion of TGA; however, this sign is not pathognomonic and could be present in other conotruncal anomalies such as common arterial trunk and some forms of double-outlet RV. An I-shaped appearance of the arterial vessel in the fetal upper mediastinum increases the suspicion of TGA. In this review, we observed that detailed analyses of the outflow tracts on cardiac ultrasound screening served as a clue to improve the diagnosis of TGA in utero. The diagnosis of TGA in fetuses has been traditionally confirmed by identifying the bifurcation of the vessel from the LVOT, which is not easy to achieve. However, the LVOT should be assessed if a long vessel with a rightward reverse curvature arises in the aorta.

ORCID: Nathalie Jeanne Bravo-Valenzuela: https://orcid.org/0000-0003-1491-4877; Alberto Borges Peixoto: https://orcid.org/0000-0002-1655-3609; Edward Araujo
Júnior: https://orcid.org/0000-0002-6145-2532

\section{Author Contributions}

Conceptualization: Araujo Júnior E. Data acquisition: Peixoto AB. Data analysis or interpretation: Bravo-Valenzuela NJ. Drafting of the manuscript: Bravo-Valenzuela NJ, Peixoto AB. Critical revision of the manuscript: Araujo Júnior E. Approval of the final version of the manuscript: all authors.

\section{Conflict of Interest}

No potential conflict of interest relevant to this article was reported.

\section{Acknowledgments}

The authors acknowledge Liana Bravo-Valenzuela e Silva, a graphic designer at Pedicor Pediatric Cardiology center in Brazil, for editing the figures.

\section{References}

1. International Society of Ultrasound in Obstetrics \& Gynecology. Cardiac screening examination of the fetus: guidelines for performing the 'basic' and 'extended basic' cardiac scan. Ultrasound Obstet Gynecol 2006;27:107-113.

2. International Society of Ultrasound in Obstetrics \& Gynecology, Carvalho JS, Allan LD, Chaoui R, Copel JA, DeVore GR, et al. ISUOG Practice Guidelines (updated): sonographic screening examination of the fetal heart. Ultrasound Obstet Gynecol 2013;41:348-359.

3. Donofrio MT, Moon-Grady AJ, Hornberger LK, Copel JA, Sklansky MS, Abuhamad A, et al. Diagnosis and treatment of fetal cardiac disease: a scientific statement from the American Heart Association. Circulation 2014;129:2183-2242.

4. Bartlett JM, Wypij D, Bellinger DC, Rappaport LA, Heffner LJ, Jonas $\mathrm{RA}$, et al. Effect of prenatal diagnosis on outcomes in D-transposition of the great arteries. Pediatrics 2004;113:e335-e340.

5. Paladini $D$, Volpe P, Marasini $M$, Russo MG, Vassallo $M$, Gentile $M$, et al. Diagnosis, characterization and outcome of congenitally corrected transposition of the great arteries in the fetus: a multicenter series of 30 cases. Ultrasound Obstet Gynecol 2006;27:281-285.

6. Chew C, Halliday JL, Riley MM, Penny DJ. Population-based study of antenatal detection of congenital heart disease by ultrasound examination. Ultrasound Obstet Gynecol 2007;29:619-624.

7. van Velzen CL, Haak MC, Reijnders G, Rijlaarsdam ME, Bax CJ, Pajkrt $E$, et al. Prenatal detection of transposition of the great arteries reduces mortality and morbidity. Ultrasound Obstet Gynecol 2015;45:320-325.

8. Escobar-Diaz MC, Freud LR, Bueno A, Brown DW, Friedman KG, Schidlow $D$, et al. Prenatal diagnosis of transposition of the great 
arteries over a 20-year period: improved but imperfect. Ultrasound Obstet Gynecol 2015;45:678-682.

9. Garne E, Loane M, Dolk H, De Vigan C, Scarano G, Tucker D, et al. Prenatal diagnosis of severe structural congenital malformations in Europe. Ultrasound Obstet Gynecol 2005;25:6-11.

10. Hoffman JI, Kaplan S. The incidence of congenital heart disease. J Am Coll Cardiol 2002;39:1890-1900.

11. Unolt M, Putotto C, Silvestri LM, Marino D, Scarabotti A, Valerio $M$, et al. Transposition of great arteries: new insights into the pathogenesis. Front Pediatr 2013;1:11.

12. Van Praagh R. Transposition of the great arteries. II. Transposition clarified. Am J Cardiol 1971;28:739-741.

13. Yagel $S$, Arbel R, Anteby EY, Raveh D, Achiron R. The three vessels and trachea view (3VT) in fetal cardiac scanning. Ultrasound Obstet Gynecol 2002;20:340-345.

14. Allan L, Hornberger L, Sharland G. Textbook of fetal cardiology. London: Greenwich Medical Media Limited, 2000;261-273.

15. Vinals F, Ascenzo R, Poblete P, Comas C, Vargas G, Giuliano A. Simple approach to prenatal diagnosis of transposition of the great arteries. Ultrasound Obstet Gynecol 2006;28:22-25.

16. Huhta JC. Evaluating the fetus with transposition. Cardiol Young 2005;15 Suppl 1:88-92.

17. Donofrio MT, Skurow-Todd K, Berger JT, McCarter R, Fulgium A, Krishnan $A$, et al. Risk-stratified postnatal care of newborns with congenital heart disease determined by fetal echocardiography. J Am Soc Echocardiogr 2015;28:1339-1349.

18. Van Praagh R. What determines whether the great arteries are normally or abnormally related? Am J Cardiol 2016;118:1390-1398.

19. Allen HD, Driscoll DJ, Shaddy RE, Felters TF. Moss and Adams's heart disease in infants, children and adolescents. 8th ed. Baltimore, MD: Williams and Wilkins, 2013;48-51.

20. Paladini D, Rustico M, Todros T, Palmieri S, Gaglioti P, Benettoni A, et al. Conotruncal anomalies in prenatal life. Ultrasound Obstet Gynecol 1996;8:241-246.

21. Galindo A, Mendoza A, Arbues J, Graneras A, Escribano D, Nieto 0 . Conotruncal anomalies in fetal life: accuracy of diagnosis, associated defects and outcome. Eur J Obstet Gynecol Reprod Biol 2009;146:55-60.

22. Yoo SJ, Lee YH, Kim ES, Ryu HM, Kim MY, Choi HK, et al. Threevessel view of the fetal upper mediastinum: an easy means of detecting abnormalities of the ventricular outflow tracts and great arteries during obstetric screening. Ultrasound Obstet Gynecol 1997:9:173-182.

23. Yoo SJ, Lee YH, Cho KS. Abnormal three-vessel view on sonography: a clue to the diagnosis of congenital heart disease in the fetus. AJR Am J Roentgenol 1999;172:825-830.

24. Vinals F, Heredia F, Giuliano A. The role of the three vessels and trachea view (3VT) in the diagnosis of congenital heart defects. Ultrasound Obstet Gynecol 2003;22:358-367.
25. McGahan JP, Moon-Grady AJ, Pahwa A, Towner D, Rhee-Morris L, Gerscovich EO, et al. Potential pitfalls and methods of improving in utero diagnosis of transposition of the great arteries, including the baby bird's beak image. J Ultrasound Med 2007;26:1499-1510.

26. Rizzo G, Capponi A, Cavicchioni O, Vendola M, Pietrolucci ME, Arduini D. Application of automated sonography on 4-dimensional volumes of fetuses with transposition of the great arteries. J Ultrasound Med 2008;27:771-776.

27. Turan $S$, Turan OM, Desai $A$, Harman CR, Baschat AA. First-trimester fetal cardiac examination using spatiotemporal image correlation, tomographic ultrasound and color Doppler imaging for the diagnosis of complex congenital heart disease in high-risk patients. Ultrasound Obstet Gynecol 2014;44:562-567.

28. Araujo Junior E, Rolo LC, Nardozza LM, Moron AF. Fetal cardiac evaluation by $3 D / 4 D$ ultrasonography (STIC): what is its real applicability in the diagnosis of congenital heart disease? Rev Bras Cir Cardiovasc 2013;28:III-V.

29. Goncalves LF, Lee W, Chaiworapongsa T, Espinoza J, Schoen ML, Falkensammer $\mathrm{P}$, et al. Four-dimensional ultrasonography of the fetal heart with spatiotemporal image correlation. Am J Obstet Gynecol 2003;189:1792-1802.

30. Shih JC, Shyu MK, Su YN, Chiang YC, Lin CH, Lee CN. 'Big-eyed frog' sign on spatiotemporal image correlation (STIC) in the antenatal diagnosis of transposition of the great arteries. Ultrasound Obstet Gynecol 2008;32:762-768.

31. Tongsong $T$, Tongprasert F, Srisupundit $K$, Luewan $S$. The complete three-vessel view in prenatal detection of congenital heart defects. Prenat Diagn 2010;30:23-29.

32. Menahem S, Rotstein A, Meagher S. Rightward convexity of the great vessel arising from the anterior ventricle: a novel fetal marker for transposition of the great arteries. Ultrasound Obstet Gynecol 2013;41:168-171.

33. Ishii Y, Inamura N, Kawazu Y, Kayatani F, Arakawa H. 'I-shaped' sign in the upper mediastinum: a novel potential marker for antenatal diagnosis of $\mathrm{d}$-transposition of the great arteries. Ultrasound Obstet Gynecol 2013;41:667-671.

34. Palatnik A, Gotteiner NL, Grobman WA, Cohen LS. Is the "I-Sign" in the 3-vessel and trachea view a valid tool for prenatal diagnosis of D-transposition of the great arteries? J Ultrasound Med 2015;34:1329-1335.

35. Ravi P, Mills L, Fruitman D, Savard W, Colen T, Khoo N, et al. Population trends in prenatal detection of transposition of great arteries: impact of obstetric screening ultrasound guidelines. Ultrasound Obstet Gynecol 2018;51:659-664.

36. Bravo-Valenzuela NJ, Peixoto AB, Araujo Junior E, Da Silva Costa F, Meagher $S$. The reverse boomerang sign: a marker for first-trimester transposition of great arteries. J Matern Fetal Neonatal Med 2019;32:677-680. 